\title{
Iron-Catalyzed Asymmetric Hydrosilation of 1,1-Disubstituted Alkenes
}
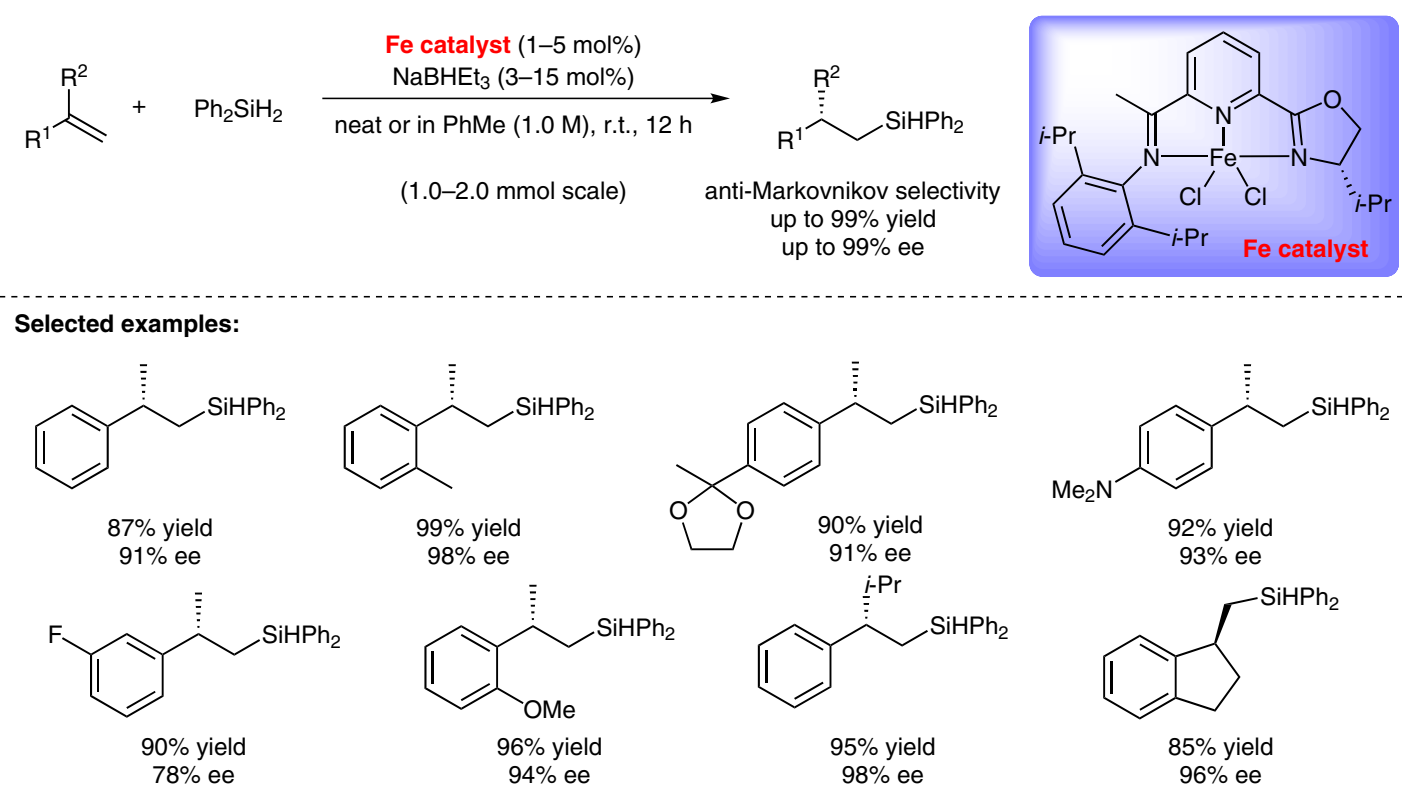

Further derivatizations:

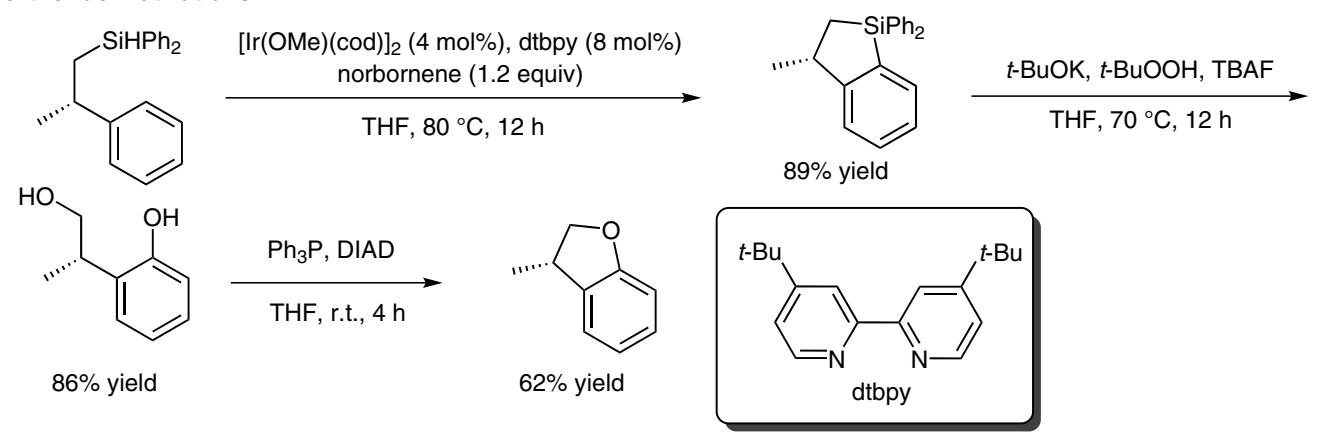

Significance: Chiral organosilicon compounds have important applications in selective $\mathrm{C}-\mathrm{C}$ bond-forming reactions. While an asymmetric alkene hydrosilylation provides a direct route to such scaffolds, the use of 1,1-disubstituted alkenes is rather elusive. For a racemic example, see: J. Am. Chem. Soc. 2004, 126, 13794. Herein, Bart et al. present a highly enantioselective method for the anti-Markovnikov hydrosilylation of 1,1disubstituted alkenes catalyzed by an iron complex.

SYNFACTS Contributors: Mark Lautens, Christine M. Le Synfacts 2015, 11(5), 0497 Published online: 17.04.2015 Dol: 10.1055/s-0034-1380562; Reg-No.: L03415SF

\section{Category}

Metal-Catalyzed Asymmetric

Synthesis and

Stereoselective

Reactions

\section{Key words}

iron

hydrosilylation

organosilicon

compounds

anti-Markovnikov

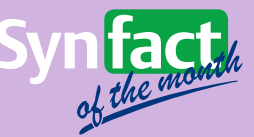

with a variety of ortho-, meta- and para-substituted aryl rings tolerated on the alkene. Sensitive aldehyde and ketone functionalities must first be protected as the acetal or ketal. In addition to the use of styrene derivatives, aliphatic 1,1-disubstituted olefins could be applied. The authors demonstrate that the products can be further functionalized to yield chiral 3-substituted Si- or $\mathrm{O}$-containing rings. 